\title{
Teachers' Understanding of Generalizing and Justifying in a Professional Development Course
}

\author{
Leonor Santos $^{1^{*}}$ (D), Joana Mata-Pereira ${ }^{1}$ (D), João Pedro da Ponte ${ }^{1}$ (D), Hélia Oliveira ${ }^{1}$ \\ ${ }^{1}$ Instituto de Educação, Universidade de Lisboa, PORTUGAL
}

Received 6 August 2021 - Accepted 17 November 2021

\begin{abstract}
A teaching practice consistent with the development of students' mathematical reasoning requires teachers to hold a profound understanding of mathematical reasoning. The aim of this research is to study the development of middle and secondary mathematics teachers' understanding about the processes of generalizing and justifying in a professional development course. Data collection included observation of the course sessions, with video recordings, and document collection of teachers' and their students' productions. A qualitative in-depth analysis was carried out focusing on the ways and complexity of generalizing identified by the teachers. The results indicate that teachers progressively focus their attention on these reasoning processes, identifying and characterizing them. The way the course was designed and enacted appears to have contributed to enable the teachers to deepen their understanding of two central mathematical reasoning processes, generalizing and justifying, in addition to their ability to foster and identify such processes in the work with their students.
\end{abstract}

Keywords: generalizing, justifying, mathematical reasoning, teacher education, teachers' understanding of reasoning processes

\section{INTRODUCTION}

The claim that the study of mathematics promotes the development of reasoning is widely acknowledged. However, a narrow and superficial view of mathematical reasoning usually underlies this idea. The need to look more deeply into the mathematical reasoning that can be developed at school has been acknowledged in recent years. In their "mathematical proficiency" model, Kilpatrick et al. (2001) give prominence to adaptive reasoning in which they include deductive and inductive processes. In the United States, the Common Core curriculum document (NGACBP \& CCSSO, 2010) highlights eight mathematical practices, of which three make explicit reference to aspects of mathematical reasoning. More recently, the mathematical literacy model for the PISA 2021 Study adds mathematical reasoning to problem solving (OECD, 2018), thus reinforcing the importance of this dimension of the mathematical activity.
However, it is necessary to know how the importance of mathematical reasoning indicated in curriculum documents is present in classroom practice. The teaching practice of teachers is crucial for students to develop their mathematical reasoning. Teachers need to have a thorough understanding of mathematical reasoning and to be able to create appropriate opportunities for its development. In particular, teachers need to know how to select tasks, which, while promoting mathematical reasoning, are also suited to their students (Brodie, 2010). This may require a sustained change in practice (Ellis et al., 2019). Research has pointed to the need for further studies to understand how teachers may be supported to adopt a teaching practice that fosters the development of students' mathematical reasoning (Keaser, 2014).

With a view to studying ways to promote such practice, a professional development course was held for middle and secondary school mathematics teachers. The present study was undertaken within this context and sought to study the development of teachers' understanding about the processes of generalizing and

(C) 2022 by the authors; licensee Modestum. This article is an open access article distributed under the terms and conditions of the Creative Commons Attribution License (http://creativecommons.org/licenses/by/4.0/). 


\section{Contribution to the literature}

- The article aims to study the development of mathematics teachers' understanding about the processes of generalizing and justifying in a professional development course.

- The contribution of this study is to present the evolution of middle and secondary school teachers, in relation to these two central mathematical reasoning processes, based on a unified analytical framework.

- The way the course was designed and enacted, giving special relevance to collaboration, to discussion of texts and to put tasks into practice to promote students' mathematical reasoning, appears to have contributed to enable the participants to deepen their understanding of generalizing and justifying processes.

justifying. The following research questions were formulated: (i) How do the teachers, along the course, understand the process of generalizing, in its ways and complexity? (ii) How do the teachers, along the course, understand the process of justifying, in its ways and complexity?

\section{MATHEMATICAL REASONING AND REASONING PROCESSES}

The term "reasoning" is commonly used in everyday language, however this does not suggest that it carries the same meaning for those who use it. In fact, in the literature on mathematics education, several interpretations of the term may be found (Jeannotte \& Kieran, 2017). From our perspective, reasoning, in any domain, is to make justified inferences (Mata-Pereira \& Ponte, 2017). We reason when, by combining and recombining elements from information given, we arrive at new conclusions that were not originally explicit.

There are several types of reasoning. Deductive reasoning comes from the Greek tradition and underpins Logic and, more recently, Mathematical Logic studies. Inductive reasoning derives from Galileo and Bacon and is at the root of modern science. Finally, abductive reasoning owes its formulation to Pierce. Deductive reasoning leads to conclusions that are necessarily true on the basis of a set of premises. In mathematics, it is closely associated with abstraction, formalization and axiomatization (Davis \& Hersh, 1986). Inductive reasoning leads to draw conclusions from observed cases to a possible general law. Through abductive reasoning we formulate conjectures or explanatory hypotheses about unexpected phenomena (Silva, 2009). As highlighted by Pólya (1945, p. ii), "mathematics presented in the Euclidean way appears as a systematic, deductive science; but mathematics in the making appears as an experimental, inductive science".

In practice, mathematical reasoning occurs through various processes, such as conjecturing and generalizing, investigating why a generalization is true or false, justifying and refuting (Lannin et al., 2011). Generalizing and justifying are often assumed central to the work carried out in the mathematics classroom (Brodie, 2010; Stylianides et al., 2013).
Generalizing is understood as "a process that infers narratives about a set of mathematical objects or relation between objects of the set from a subset of this set" (Jeannotte \& Kieran, 2017, p. 9) or about a property common to a set of objects (Lannin et al., 2011). In other words, it is possible to generalize by broadening the set of mathematical objects on which we are working or by identifying a common property in this set. Conjecturing is a process of formulating non-arbitrary claims "about a general mathematical relation based on incomplete evidence" (Stylianides, 2008, p. 11). A generalization is the product of the process of generalizing. The formulation of conjectures and generalizations usually occurs through inductive or abductive reasoning.

Justifying is a mathematical reasoning process "that, by searching for data, warrant, and backing, allows for modifying the epistemic value of a narrative" (Jeannotte \& Kieran, 2017, p. 12). Lannin et al. (2011) present the concept of justifying in the sense of validating. According to these authors, justification occurs through the presentation of a logical argument based on already understood ideas. This logical argument must be constructed through a sequence of arguments based on ideas acknowledged as being true for a conclusion to be attained. When the conclusion reached stems from the falsity of the narrative, this is referred to as refutation instead of justification (Lannin et al., 2011). Justifying does not have to be formal and does not even have to be correct, but it is still a mathematical reasoning process (Lannin et al., 2011; Lithner, 2008). A justification is the product of the process of justifying.

\section{TEACHING AND TEACHING EDUCATION TO PROMOTE MATHEMATICAL REASONING}

A teaching practice that facilitates the development of students' mathematical reasoning is complex and demanding (Brodie, 2010). From the outset, an in-depth knowledge of mathematical reasoning is essential for teachers to plan learning experiences that will foster students' reasoning (Davidson et al., 2019), to support students in the classroom by giving them clues to proceed, and to recognize opportunities to pose new challenges to students, as an extension of the task, as 


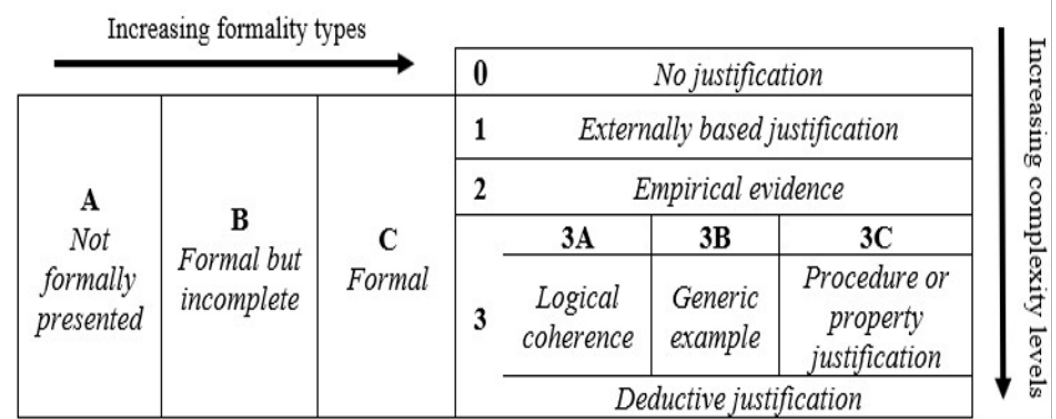

Figure 1. Levels of formality and complexity of justification (Mata-Pereira \& Ponte, 2018)

evidenced in studies with early years' teachers (Herbert \& Bragg, 2020).

Models can help teachers analyse students' justifications, identify their level and guide them to more complex levels (Sowder \& Harel, 1998). The model in Figure 1 considers the different levels of complexity and formality of the justifying process. In this model, the increasing levels of complexity shift from the absence of justification to formal justification. Some forms that the justification process can take are also indicated, such as logical coherence, the use of generic examples and mathematical procedures or properties. Increasing levels of formality shift from non-formal to formal, depending on the representations used.

It should be noted that the different levels of formality should be developed progressively. Attributing excessive importance to formal proof will exclude students from different age groups, thus removing them the opportunity to make sense and establish mathematical relationships (Stylianides, 2008). A strict focus in formal deductive logic encourages a passive attitude towards mathematics, whereby the students contact with the finished structure of this science instead of viewing it as an activity under construction (Watson, 1980). This has resulted in the recent tendency to value the undertaking of justification through informal language, making it possible to work on different mathematical reasoning processes with students from the beginning of their schooling. For example, a study with students from grades 3 and 4 showed the importance of involving them in reasoning processes, such as conjecturing, generalizing and justifying (Widjaja et al., 2020). Comparing and contrasting, through observation and construction, enabled the students to formulate conjectures and to progressively develop their ability to justify by identifying counterexamples and, sometimes, by constructing logical arguments. In a study by Hoyles and Küchemann (2002) with grade 8 students, were observed two constrains to formulate justifications: the lack of recognition of the need to justify and the lack of students' focus of attention (Mata-Pereira \& Ponte, 2012). Another study, by Mata-Pereira and Ponte (2012), with grade 7-9 students, showed that the justification process does not occur spontaneously. It is by means of the teacher's questioning that students are able to justify, using properties related to mathematical concepts and counterexamples that refute a claim.

Focusing on the work of teachers, Brodie (2010) monitored the teaching practices of a group of mathematics teachers who were working collaboratively in secondary school, and the results showed "how difficult the task of engaging learners in genuine discussion about reasoning really is" (p. 55). In addition, El Mouhayar (2020), in a study with grade 7 teachers, shed light upon two factors that may contribute to fostering the emergence of different levels of students' generalizations, namely the performance of multiple roles by the teacher (initiator of the interaction and asking for clarifications and justifications), and alternation of the type of knowledge (factual/conceptual/procedural-algorithmic and procedural-inquiry).

In order to develop practices that foster the development of students' ability to reason, the teacher must be attentive to a number of factors, such as the task's potential to promote reasoning, suitable actions to explore reasoning with students, and understanding the work produced by the students in order to support them in the most appropriate manner (Davidson et al., 2019).

The main aim of highlighting the importance of deepening the teacher's understanding of reasoning is so that he/she may be suitably equipped with the tools required for a change in practices. In this regard, a study carried out with secondary teachers pointed to "the importance of a perturbation to foster awareness of the need for a change" (Keazer, 2014, p. 177). In addition, Brodie (2010) indicates that "to improve practice, teachers need to recognize the shifts that they have made and those they still need to make" (p. 200).

Thus, teachers should be enrolled in professional development processes that provide opportunities to enhance their knowledge about how to develop students' mathematical reasoning (Borko et al., 2010; Weiss \& Pasley, 2006). In one hand, such professional development processes should be based on knowledge about teaching and learning mathematical reasoning and reasoning processes (Weiss \& Pasley, 2006). On the other hand, these professional development processes should enroll the participant teachers in exploring 
Table 1. Work developed in the professional development course

\begin{tabular}{|c|c|}
\hline Session/work & Tasks developed \\
\hline S1 & Solving and discussing PDT 1 \\
\hline Individual autonomous work & $\begin{array}{l}\text { Reading of text } 1 \text { (Meaning of mathematical reasoning, types of reasoning, and } \\
\text { reasoning processes) }\end{array}$ \\
\hline S2 & Discussion of text 1 /Solving and discussing PDT 2 \\
\hline Individual autonomous work & Reading of text 2 (Teachers' practices that promote mathematical reasoning) \\
\hline S3 & Discussion of text 2/Construction of the lesson plan for Into Practice I \\
\hline Group autonomous work & $\begin{array}{l}\text { Conclusion of the lesson plan and its implementation by all teachers of each group } \\
\text { Preparation of the oral presentation }\end{array}$ \\
\hline S4 & Oral presentations of Into Practice I and discussion \\
\hline Individual autonomous work & Reading of text 3 (Principles of design of tasks to promote mathematical reasoning) \\
\hline S5 & Discussion of text 3/Solving and discussing PDT 3 \\
\hline Individual autonomous work & Collection of materials for planning Into Practice II \\
\hline S6 & Construction of the lesson plans for Into Practice II \\
\hline Group autonomous work & $\begin{array}{l}\text { Conclusion of the lesson plan and its implementation by the teachers of each group } \\
\text { Preparation of the oral presentation }\end{array}$ \\
\hline S7 & Oral presentations of Into Practice II and discussion \\
\hline Group autonomous work & $\begin{array}{l}\text { Conclusion of the implementation by the teachers of each group } \\
\text { Preparation of the oral presentation }\end{array}$ \\
\hline S8 & Oral presentations of Into Practice II and discussion/Resolution and discussion of PDT 4 \\
\hline Individual autonomous work & Final written reflection \\
\hline
\end{tabular}

classroom tasks and how to enact those in the classroom, contributing to opportunities for reflection on their learning and the effectiveness of strategies they may use as teachers (Borko et al., 2010). Additionally, professional development processes must be supported over time, aiming teachers to integrate new knowledge into practice (Weiss \& Pasley, 2006). Therefore, it is expected that such professional development processes consider the articulation with the teachers' practice, which translates into opportunities to explore and experience the knowledge on how to promote the students' mathematical reasoning in their own classroom.

\section{THE PROFESSIONAL DEVELOPMENT COURSE}

The professional development course, from the responsibility of the authors of this paper, took the form of a workshop, and was conducted in eight face-to-face sessions $(\mathrm{S} x)$ with a total of 20 hours, plus a further 20 hours of autonomous work by the teachers. To create a favourable context for the professional development of teachers and to have an effect on their practices, the course was designed to create opportunities for sharing and reflecting on ideas and for promoting teaching practice experiences, in a collaborative context in face-toface sessions and in autonomous work moments (Borko et al., 2010; Smith, 2001).

Three different types of tasks were proposed to the teachers: to solve professional development tasks (PDT), to read and discuss texts, and to put into practice tasks to promote students' mathematical reasoning (Table 1).

The three first PDT included mathematical tasks to be proposed to students, their solutions and classroom situations. The focus of these tasks was the process of reasoning and its relation to the tasks' characteristics and the teachers' actions to promote it. For example, PDT 1 begun with the presentation of two tasks to propose to grade 7 students. The first task asked to discover a property of numbers that we get by adding three consecutive natural numbers, and the justification of the validity of that property. The second task required to show that adding four consecutive natural numbers the sum is an even number. Besides solving the tasks, the teachers' role was to indicate the characteristics that, in their view, made these tasks well fit to promote students' reasoning and to analyse students' productions and episodes of the mathematics class. In PDT 4, the teachers wrote a reflection, in groups, about the course. The three texts focus in different topics (see Table 1) and were written a professional style (two of them were published in professional journals). They have similar characteristics, such as developing some theoretical ideas illustrated by examples that are either mathematical tasks with students' solutions or mathematics classroom episodes. The objective of including these texts in the course was to help participants to construct a theoretical framework about mathematical reasoning. The texts were previously read by the teachers in autonomous work, and then discussed in face-to-face sessions, addressing in each case which were the main ideas, what was new or difficult to understand, and which implications could be drawn to teaching practice.

For the two Into Practice moments, the teachers were divided into four groups, according to the grades they were teaching at the time (grades 7, 8, 9, and grades 10 12). Each group planned two classes, one for each Into Practice moment aimed at promoting students' 
Table 2. Categories and subcategories of analysis of reasoning processes

\begin{tabular}{lll}
\hline \multirow{2}{*}{ Categories } & Generalizing & Subcategories \\
\hline Ways & - Identifying a pattern & - Empirical evidence \\
& - Identifying a property & - Generic example \\
& & - Mathematical procedures or property of objects \\
& & - Logical coherence \\
Complexity & - Proof by contradiction \\
& - Formal & - By exhaustion \\
& - Formal but incomplete & \\
& - Not formally presented & \\
\hline
\end{tabular}

mathematical reasoning, including the design or selection of a task to propose in their classrooms. The Into Practice moments finished with an oral presentation by each group to the whole group that included an explanation of the main objectives of the proposed task, the dynamics of the class, and the analysis of students' solutions focused in their features related to mathematical reasoning.

\section{METHODOLOGY}

This research adopted an interpretive approach (Schwandt, 1994), since it sought to study the development of teachers' understanding about the processes of generalizing and justifying during a professional development course. More specifically, it aimed to ascertain the ways and complexity considered by teachers in the processes of generalizing and justifying.

The selection of the participants initiated by a dissemination of this offer for an in-service teacher education workshop. A group of 16 mathematics teachers who teach students from grades 7 to 12 showed interest in participating within the proposed schedule. These were teachers with a diversified professional experience and whose teaching experience ranged between 4 and 33 years. Most of these teachers had invested in their professional development beyond their initial academic education for teaching, and seven had completed an academic master's degree in the field of Didactics of Mathematics. Most of these teachers had received their teaching degree at University of Lisbon.

All the teachers, the students from their classes and their respective parents/guardians and school heads were informed of the study's aims and of how the data collection would be carried out. Except the students, they all signed a document giving their informed consent. To guarantee anonymity, all the participating teachers were given a fictitious name.

The data collection included observation of the course sessions, with video recordings, and document collection of the answers given by the teachers to PDT, teachers' plans designed by the groups, students' productions during the Into Practice classes and teachers' written final reflection.

The data analysis has been made by the four authors of this paper, in pairs, each of these being responsible for one of the two reasoning processes considered in the study. After a systematic reading of the data, the most relevant data was selected and object of content analysis (Bardin, 2003), considering as units of analysis the intervention of a teacher or production of a teacher or a group of teachers. To be able to gain evidence of possible development of the teachers' understanding in both reasoning processes, the analysis of data was organized in two phases: a first one, that focuses on the session 1 , when the first discussion about reasoning processes occurred, and a second one, that centres on data from sessions 4,7 , and 8 where the presentations of the two Into Practice moments took place. After analysing the data according to the subcategories considered (Table 2), to guaranty quality of content analysis, such as exclusivity, homogeneity and pertinence (Bardin, 2003), each researcher selected a set of data that was discussed by the four authors. We had in some cases difficulty in interpreting what the teachers were saying, because the way they expressed themselves. These situations were solved by discussion among the four authors.

Focused on the mathematical reasoning processes of generalizing and justifying and considering the literature review and the collected data, the categories and subcategories of analysis were developed as presented in Table 2, representing a unified framework to study both reasoning processes. In particular, we considered two main kinds of generalizations - rules underlying patterns and properties of mathematical objects (Ellis, 2007; Jeannotte \& Kieran, 2017). It is to be noticed that only justification by exhaustion did not emerge in the analysis.

\section{TEACHERS' UNDERSTANDING OF GENERALIZING}

\section{The Ways of Generalizing}

In session 1, while identifying task characteristics that promote students' mathematical reasoning and aspects of students' mathematical reasoning, most teachers' 
references to generalizations where not clearly related to generalizing as a reasoning process. For example, Isabel points out an incorrect generalization from a student not explicitly as a generalization but rather as a first step into reasoning:

When he says, "Oh, if I sum the first with the second it always yields the third", it does not work, but it that case he is already beginning to reason. (Isabel, S1)

Also, in the first session, other teachers rely on other expressions as "discover" or "exploring", to refer to conjectures or generalizations.

However, some teachers occasionally made explicit references to generalizing. When doing so, they identified generalization or conjecture as a component of mathematical reasoning and associated this feature with the identification of a pattern or regularity:

"When they are looking for a pattern, a generalization, they begin by making initial attempts, and this is how they start to put their reasoning together." (Julia, S1)

Teachers also make reference to conjectures or generalizations as the identification of patterns or regularities in most situation of the presentation of Into Practice I. These references considered mostly conjectures or generalizations based on specific cases:

In general, they all tested one, two or three examples, and then they tried to formulate a conjecture [generalization]. (Maria, grade 9 group, S4)

Then, in question 2 [ the aim was] for them to check alternately the number of edges of the prisms, sometimes they were even, sometimes odd, depending on how many sides the polygon had, and then to generalize a relationship between the parity of the number of edges of the prism and the [number of] sides of the polygon. (Vitor, grade 8 group, S4)

Although sometimes the identification of patterns was linked to conjecturing, the conjectures referred by the teachers had a general nature, thus being implicitly related to the generalizing process.

The reference to generalization as the identification of a pattern was again evident in the presentations of Into Practice II, but with a more consistent formulation, such as in grade 8 group's planning task regarding an issue that aimed to obtain the general term of a sequence (Figure 2). This teachers' reference to generalizing also seems to reflect the principles to task design as it refers to construction and one of the principles proposed by text 3 (S4) is to include questions that promote generalizations based on construction.
Reasoning and types of reasoning identified and justification

- Reasoning type: Inductive

Inference of a rule through observation of what is common in several cases

- Reasoning process and assumed form: Generalization (construction) by recognizing a pattern

The main aim of this question is to find the general term $\frac{1}{2^{n}}$, recognizing that $2,4,8, \ldots$ are powers of 2 , i.e., make a generalization.

Figure 2. Part of grade 8 group's planning in Into Practice II

1.2 Identify task characteristics that, in your opinion, make those tasks suitable to enhance students' mathematical reasoning. Justify your answer.

The tasks encourage students' exploration, even to students with different

rhythms, as while one might begin with particular cases, other might venture

themselves in abstraction and geveralization

The need to identify a property and ustify it promotes that at some point the

student feel encouraged to generalize.

Figure 3. Teresa's answer about characteristics of the task in S1

This idea of generalizing as an identification of a pattern was then reinforced during the presentation:

We will infer a rule based on the observation of what is constant in some specific cases. Generalization, in this case we expected what actually happened, by construction, after recognition of a pattern. (Sonia, grade 8 group, S7)

From the very first session, teachers also referred to generalizing as the identification of a property. The task proposed in the first session included a generalization as an identification of a property. Whereas the teachers rarely referred to generalizing in this first session, a single situation emerged where one teacher (Teresa) indicates that a generalization may be formulated by the identification of a property (Figure 3).

In this situation the teacher recognizes not only the identification of a property as a generalization, but also the difference between this and generalizing as the identification of a pattern by "beginning from particular cases".

In the presentation of Into Practice $I$ and II, the reference to generalization as an identification of a property also emerged. In Into Practice I, in the context of grade 8 task, Luisa referred to the identification of a property, implicitly common to a set of objects, corresponding to 
2. Regarding prisms, the total number of edges will be an even or odd number? Justify your answer.

\section{Yes, because when the number of sides of the prisin's base is even, the edges are too.}

\section{The number of edges is the triple of the sides.}

Example of a prism

\section{And if the number of}

sides is odd, the number

\section{of edges also is.}

Figure 4 . Solution of a group of students, commented by Luisa

3. What fraction represents the part of the cut grass in the $1^{\text {st }}$ day? And in the $2^{\text {nd }}$ ?... And in the c. $\mathrm{n}^{\text {th }}$ day?

$$
\begin{aligned}
& \left.\begin{array}{cccc}
\frac{1}{2} & 5^{\text {th }} \text { day } & \frac{1}{9^{\text {th }} \text { day }} & \frac{1}{2} \\
\frac{1}{\cos 512} & \frac{1}{2}
\end{array}\right)=\frac{1}{4}
\end{aligned}
$$

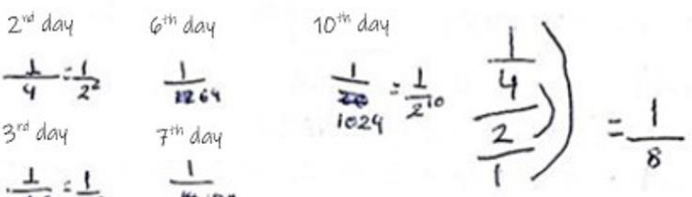

$$
\begin{aligned}
& \frac{1}{68}=\frac{1}{2^{3}} \quad \frac{1}{128} \\
& 4^{\text {th }} \text { day } \quad \frac{1}{16} \quad \frac{8^{\text {th }} \text { day }}{16256} \quad n^{\text {th }} \text { day }=\frac{1}{2^{n}}
\end{aligned}
$$

Figure 5. Students' solution, commented by Vitor

the generalization present in the answer of a group of students (Figure 4).

In the second question, they had already worked out it was triple, they had immediately concluded that the total number of edges of the prism was the triple of the number of sides of the polygon base and when they got to the third [question] they called me: "what am I supposed to do here? I've already answered, what more can I do?" and I said "OK, but can you explain this property better?" (Luisa, grade 8 group, S4)

On the other hand, in Into Practice II, when analysing the generalization presented by the students (Figure 5), Vitor explained that they had identified a regularity which enabled the construction of the sequence ("a division by 2 "), but he also referred to the students' recognition of a mathematical property of the numbers obtained, which allowed them to arrive at the generalization.

The students recognise from one day to the next that a division by 2 , because here they have $1 / 2$ divided by 2 , here $1 / 4$ divided by 2 , will lead to these fractions. And then they recognise the powers of 2 property of the denominator and generalize. (Vitor, grade 8 group, S7)
For some of the teachers, considering generalizations as the identification of a pattern and the identification of a property was, in fact, a novelty or a relevant learning aspect of the teacher professional course, as they refer in their final written reflections:

During the course I had the opportunity to learn
about mathematical reasoning processes . . .
[namely] generalization [that] . . . can assume
several forms as recognizing a pattern or a
property common to a set of objects, [and]
broaden the domain of validity of a property to a
broader set of objects. (Margarida, final reflection)

The reflection about reasoning processes and their implications in teaching was also an important moment of learning. Generalizing . . . goes from the observation, construction, or transformation of previous knowledge to recognizing a common pattern or property, broadening the domain of validity of a property. (Isabel, final reflection)

In summary, the meaning of generalization is mostly associated with the identification of a pattern or the identification of a property. Whereas some of these meanings emerged occasionally in the first sessions, there were also situations in these first sessions where the meaning of generalizing was not clear and this process was not identified as such, but instead with the processes of exploring or trying some particular cases. Regarding the identification of a pattern or regularity, this association seems to be present from the very beginning of the course, but the association is more explicit during the presentations of experiences of the two Into Practice moments. Generalization by identification of a common property of a set of objects was most salient in Into Practice II, albeit it also emerged in a situation in the first session and also in a more implicit form in Into Practice I.

As such, the ways of generalizing identified by the teachers emerged from their activities in the first task, but were more visible as they moved towards Into Practice I and later to Into Practice II. There were even teachers that recognized that these were new ideas for them. Along this path, it is visible the enactment of some of the ideas discussed in the course, as the principles of design of tasks to promote mathematical reasoning (text 3) in planning and presenting Into Practice II (e.g., Figure 2 and subsequent teacher's comment).

\section{The Formality of Generalization}

Teachers' identification of a close relationship between generalization and representation in algebraic language became clear early on in the course. This relationship began to emerge with reference to "algebraic generalization": 


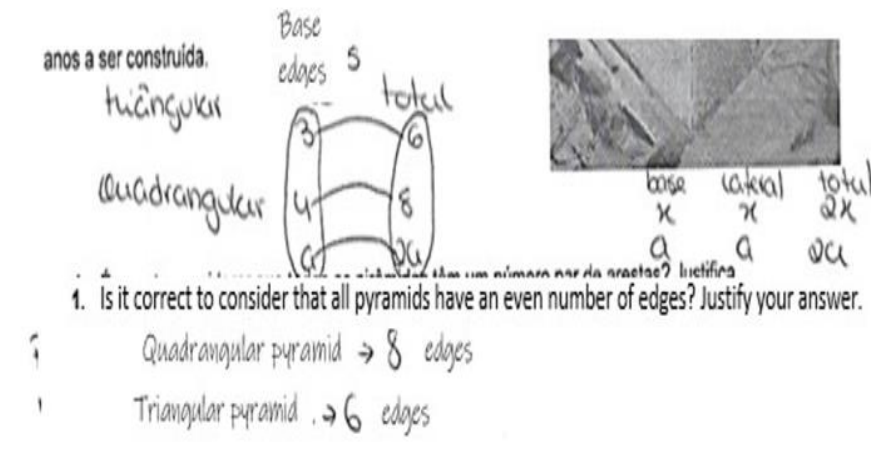

The vumber of edges of a pyramid is always even, becouse they are: wainber of edges of the base $\times 2$

Figure 6. Other student's solution, commented by Vitor

We are talking about numbers and they take numbers, in examples with numbers, instead of going straight to an algebraic generalization. (Vitor, S1)

In the first presentation of Into Practice I, the grade 7 group did not refer to the process of generalizing (or conjecturing) at any time in their presentation. In view of this situation, during the discussion of the presentation, the teacher educator asked a question related to this process. The teacher's response reflects the strong connection assumed between generalizing and representation in algebraic language:

Teacher educator: And did any of the students generalize?

Marta: No (...) In my case, they didn't work at all on algebraic expressions. (grade 7 group, S4)

This association was also highlighted by Vitor when referring to one student's response to the task that sought to establish the relationship between the total number of edges of a pyramid and the number of sides of a polygon base (Figure 6). The teacher mentioned the generalization represented in the diagram, but highlighted the generalization that took the $x$ variable.

The student here: base edges 3 and in total 6, 4 is 8 , if it's a it's $2 \mathrm{a}$, and so he's already making a generalization. (...) the student gives some examples here, but manages to generalize in the next stage: at the base it has $\mathrm{x}$ or $\mathrm{x}$ edges, on the side also, therefore in total it has $2 x$, I found this very interesting. (Vitor, grade 8 group, $\mathrm{S} 4$ )

Also, in the grade 9 group, Vera seems to consider the students' conclusion as a generalization only if they considered variables as measurements of the rectangle. This teacher seemed not to consider a generalization a statement that is based on a limited number of specific cases:
I had a group that only worked with concrete measurements and reached the conclusion through several examples that the measurement of the area of the final rectangle decreased by $1 \%$ and the other groups managed to come to a generalization [using algebraic language]. (Vera, grade 9 group, $\mathrm{S} 4$ )

In these teachers' presentations, representation in algebraic language took on a central role, demonstrating the importance given by teachers to formally presented generalizations.

The formality of generalization was also highlighted in the presentation of Into Practice II, for example when teachers referred to a generalization that was operationalized through an algebraic expression (rule or law) modelling the proposed situation. An example of this situation is the intervention of Pedro on the students' solutions to the afore-mentioned task on the number of strokes of the ball on a table identical to a snooker table:

I suddenly had several groups starting to work on the ratios between the tables, they ignored the fact that they were slightly different, because they understood that the pattern repeated itself, so they just worked with those elements and in that way discovered some laws. They didn't all manage to properly come up with a generalization. Only one group, in fact. (Pedro, grades 10-12 group, S7)

Additionally, informal generalizations were also valued by the teachers in this final phase of the course.

The use of other representations in the process of generalizing was highlighted, where modelling of the situation through more suggestive representations was considered crucial to obtain the desired generalization:

They then used their pencil cases to make 6 people and did the whole strategy and understood the expression easily. (...) In fact, it was this form of active representation they were working on that helped them to get there easily. (...) The ones who managed it out of my groups were the ones who didn't write it down straight away [the algebraic expression]. I mean, some of them wrote it (...) but others didn't, and it was a good thing that they didn't because they managed not to lose the context. (Rita, grade 9 group, S8)

In another situation, based on a task seeking to obtain the general term of a sequence, Luisa also considered representation in a table as being fundamental to students' generalizing: "Suggesting a table was very effective in terms of the kids managing to generalize." (Luisa, grade 8 group, $\mathrm{S7}$ )

In summary, from the very beginning of the course, the teachers valued generalizations in algebraic 


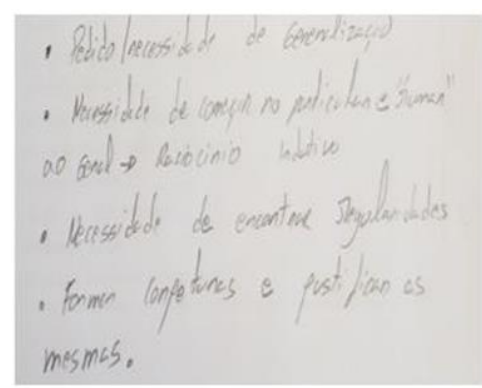

- Asking/the need of generalizing - The need to begin with the particular to move to the general - inductive reasoning - The need to find regularities - The need to formulate conjectures and its justifications

Figure 7. Characteristics of tasks that promote mathematical reasoning, indicated by Vera

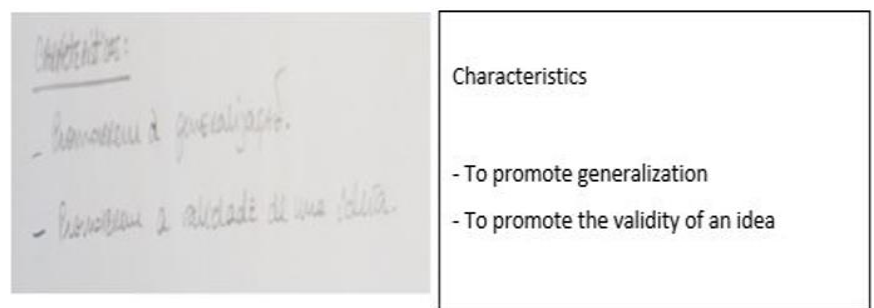

Figure 8. Characteristics of tasks that promote mathematical reasoning, indicated by Alda

language and formally presented. Nevertheless, in the second part of the course, less formal generalizations were also considered as relevant, particularly when teachers analysed students' solving processes. The progressive acceptation by teachers of informal ways of generalizing (the same occurred with justifying) was the reflection that teachers made regarding students' productions and classroom episodes that consider informal ways of justification. Such examples arise in the first two texts and in the tasks carried out.

\section{TEACHERS' UNDERSTANDING OF JUSTIFYING}

\section{The Ways of Justifying}

In the teachers' answer to the second part of PDT 1 emerged the idea that the justification process is related to validating conjectures and justifications (Figure 7 and Figure 8).

In this session, teachers almost did not refer how the process of justifying may be enacted. However, since the beginning of the course, it is clear that for the teachers $a$ general rule cannot be justified simply by verifying some particular cases, as it was referred by Rita when analysing an episode presented in PDT 1 . According to her, to study some cases may be useful to conjecturing, but to justify it is necessary to use an algebraic representation, in other words, to consider a general case:

To discover the properties, they will experiment some examples and formulate conjectures. An algebraic representation will be made a-posteriori to prove that any number satisfies the correspondent conditions. (Rita, grade 9 group, S1)

During the PD sessions, in analyzing students' productions, Pedro and Marta restated this assumption. As they analyzed the productions of their students, they verified with surprise that some of them just verified one or two cases, considering that such procedure was enough to justify the response:

Two examples do not prove that it is always different. (Pedro, grades 10-12 group, S4)

I didn't think this would crop up very much, but in fact in most of the groups whose work I was checking, they had this: they would verify for a term, or for two, and that was enough. (Marta, grade 7 group, $\mathrm{S} 8$ )

The teachers considered the use of generic examples as a valid way of justifying. This may be observed in the discussion of grade 8 students' answers to two questions in Into Practice I. Isabel made the following comment on the solution provided by a group of students (Figure 9), and indicated that they may had chosen generic examples, since they chose a case of an even and an odd number to draw conclusions to both situations:

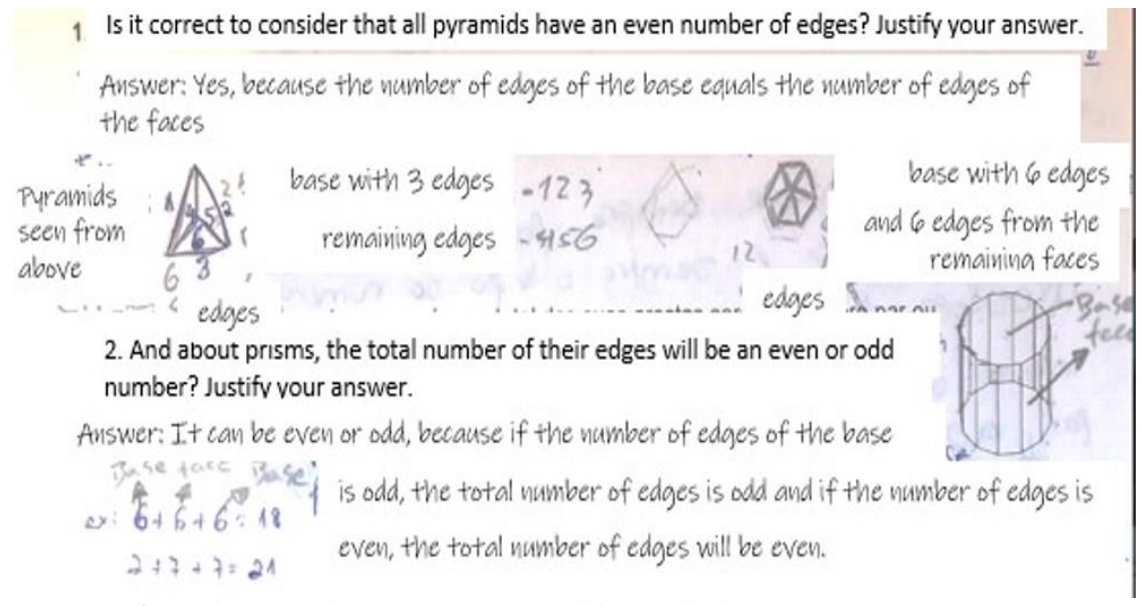

Figure 9 . Solution of a group of grade 8 Students, commented by Isabel 


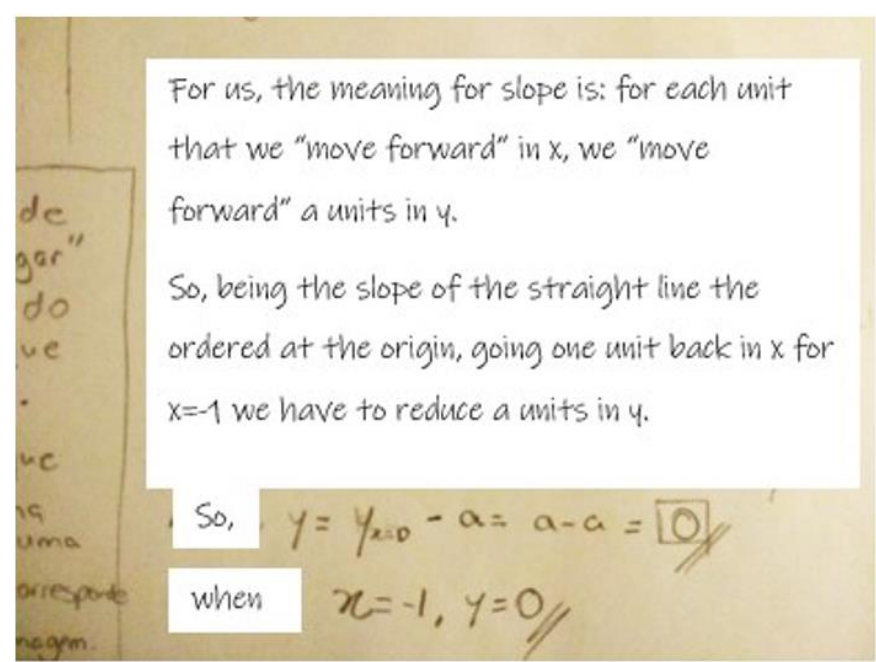

Figure 10. Solution of a group of grade 12 students, commented by Paula

I thought that it might have been somewhat intentional because they gave another example with an even number of base sides and then an odd number, and then they did a bit more here, in other words "it could be odd or even because..." and the "because" is more in line with a justification, and they claimed to have found a relationship between when it was even and when it was odd. (Isabel, grade 8 group, S4)

The use of properties of mathematical objects was noticed by teachers in other justifications. This was the case with the teachers of grade 8 students, in the second task, when justifying the truth of the claim "The fraction $(1 / 2 n)$ is never zero, for $n € N^{\prime \prime}$, using a property of zero, as explained by Alda:

"They justified that the claim was true by using [a] property ... They thought 'So, to multiply and obtain a zero, there has to be a zero there'." (Alda, grade 8 group, S7)

It was also the case of Paula who pointed out a justification using the property of mathematical objects, presented by her students in grade 12 . The students needed to characterize the family of straight lines $y=$ $a x+a, a \in \mathbb{R}$. Paula indicated that the students used the meaning of slope to justify their answer (Figure 10).

Then, these here are the strongest aspects. A solution that I was not expecting. The students used the slope, that is, they started out by saying that if the slope is each one moves up a, so if we go -1 backwards a moves down and we are left with the point $(-1,0)$, and so it is justified, and I watched them solve it and agreed. Therefore, it is perfect. (Paula, grades 10-12 group, S4)

In the grade 8 group, Luisa referred to a justification that used logical coherence, as the students had
A division may only be 0 when the numerator is 0 what is not the case, because the numerator is always 1 .

Figure 11. Solution of a group of students from grade 8 , commented by Luisa

accomplished a chain of mathematical propositions, as she explained:

I think that the first one is more similar to a justification by logical coherence... They had to prove that $1 / 2 \mathrm{n}$ was never zero. Then they said "It's true, because natural numbers can't have negatives or zero, therefore all natural numbers raised to a natural number, have to be a natural number" . . . And this fraction can't be zero because the numerator is always 1 ". So, here we can see a chain of properties. (Luisa, grade 8 group, S7)

As Luisa also explained, another group used a justification that is akin to a proof by contradiction to justify that it can never yield zero (Figure 11):

Then, there's another justification that I think falls more [in] proof by contradiction, although it is not an "absurdity" that is totally "absurd". (Luisa, grade 8 group, $\mathrm{S7}$ )

Being able to identify different ways of justifying, evidenced previously, was a learning that occurred during the course as several teachers referred in their final written reflections. According to them, it was important to reflect about these processes, allowing them to clarify and distinguish different concepts, as well as improving their practices:

I consider that it was very important for me, as teacher, to reflect about the notion of mathematical reasoning and to distinguish the processes of mathematical reasoning evidenced by students in their written solution of the tasks and in discussion. For example, justifying and explaining became actions with two different meanings. (Alda final reflection)

It has been also important the reflection . . . in particular about the processes of reasoning and its implication for practice.. . the justification associated to deductive reasoning that uses definitions, axioms, properties, principles and representations, relating them while maintaining logical coherence, using generic examples or counter examples, by exhaustion or absurdity, in order to validate knowledge. (Isabel, final reflection) 
Nevertheless, some teachers pointed out that it is not always easy for them to recognize the ways of justifying used by their students, as Maria assumes in her final written reflection:

"I recognize better the difficulty and complexity... to identify the processes of reasoning used by students in solving the tasks."

In summary, the teachers recognized the importance of reflecting about the ways of justifying and their understanding of these ways evolved along the course. In the first session, they did not mention it. It came up only the idea, expressed by teachers, that the truth of a general rule cannot be justified by simply verifying some particular cases. This situation emerged from the students' productions presented and the classroom episodes analysed in the PDT 1. It was while analysing the students' productions of different mathematical tasks, during the two moments of Into Practice that the teachers referred several ways of justifying. These moments were fruitful on the identification of these ways of justification because the teachers could confront different strategies (they had the students' productions from three or more classes). Also, a text that explicitly enunciates different ways of justifying was previously discussed, calling the teachers' attention to it.

\section{The Formality of Justifying}

In the first session, that was based in the PDT 1, and since justification was not object of great attention from teachers, there was no reference to the levels of formality that this process may assume. It is from the presentations of Into Practice I and II that the teachers indicated the ideas that they have about the levels of formality in justification.

In the teachers' discourse, justification emerged in relation to deductive reasoning:

"Deductive reasoning was present. They used claims sequenced in a logical manner to answer the question . . . , they used logical reasoning to justify the answer." (Alda, grade 8 group, S7)

Thus, the teachers expected that the students produced a formal justification. This was the case indicated by the arrow and balloon added by Marta, a grade7 teacher, during her group oral presentation of Into Practice II. The group of students were justifying whether a given value is a term of a sequence, using the general term already obtained and verifying if they obtained a natural number (Figure 12).

An incomplete formal process when justifying was also recognized by teachers analysing their students' work. For example, Margarida, for the same mathematical question (Figure 11), highlighted a solution where students explored some cases and provided a justification based on this empirical evidence (Figure 13).

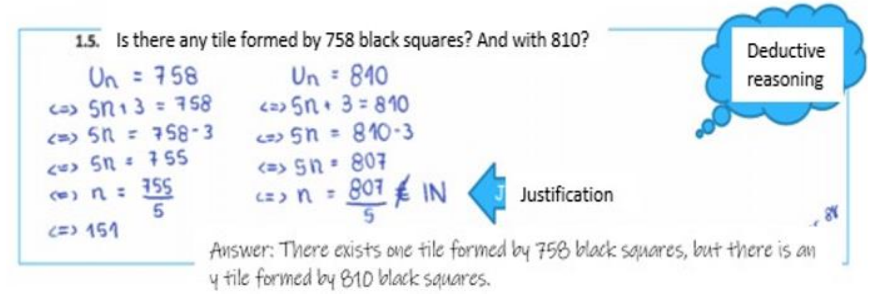

Figure 12. Solution of a group of grade 7 students, commented by Marta

1.5. I Is there any tile formed by 758 black squares? And with 810 ?

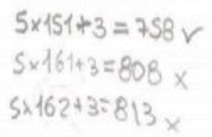

Answer: There is no natural number that added to 3 is 810

Figure 13. Solution of a group of grade 7 students, commented by Margarida

It is true, because all the natural numbers cannot be negative or zero, so

all the natural numbers powered to a natural number have to be a

natural number. And, this fraction cannot ever be zero because the

numerator is always 1

Figure 14. Solution of a group of grade 8 students, commented by Luisa

In her opinion, the students used an incomplete formal process, since they did not explicitly clarify how they were able to guarantee that 810 was not a term of the given sequence:

I quite liked this reasoning here too. To say there is no term for 810 , they find tile 161 and say it's equal to 808 squares (...). And then 162 and say it's 813 . So, as that one was 810 , they managed to conclude that there is not one and put a cross there. This is how they answered: "There is no natural number that by adding 3 results in $810 "$. They tried, but then they did not... in their conclusion, they ended up not being very explicit. (Margarida, grade 7 group, S8)

Logical coherence of a non-formal nature was also accepted by the teachers as valid to produce justifications, given the students' age level and their expected mathematical knowledge. This was the case pointed out by Luisa for a group of grade 8 students who justified the truth of the claim given to them in the Into Practice II task using current, informal language (Figure 14).

Luisa interpreted the way of justifying that students used with no comment on their representation: 


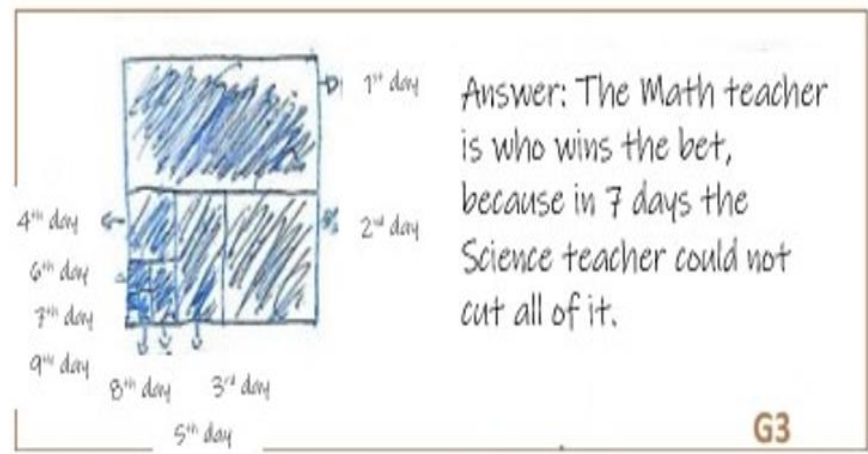

Figure 15. Solution of another group of grade 8 students, commented by Luisa

"I consider more a justification by logical coherence." (Luisa, grade 8 group, S7)

Another no formal justification, recurring to a pictorial representation (Figure 15), was also well received by Luisa:

The two examples I have here, a justification at the level of calculation, another more pictorial justification, but they are concerned about arriving at a valid conclusion. (Luisa, grade 8 group, S7)

In summary, the teachers accepted several levels of formality expressed in different representations. These results emerged from the analysis of the students' solutions of the tasks used in the Into Practice moments that were in a great amount number since the teachers that were involved in the present course have their own classes. Therefore, they were taking into account the students' grade level and their correspondent mathematical knowledge. Moreover, the learning objectives of the tasks proposed in the lessons discussed in the course, were clearly related by the teachers to the students' mathematical reasoning and not to their capacity to use symbolic representation.

\section{DISCUSSION}

By working on the tasks proposed in the course, the teachers began to focus more on the processes of generalizing and justifying. This was quite apparent in the diversity of ways the teachers referred these reasoning processes when analysing students' productions.

Throughout the course, the teachers associated generalization with the identification of a pattern or regularity, in line with the teachers in the study of Stylianides (2008). They also associated generalization to a property that was common to several objects. The initial ideas presented by the teachers on generalization focused on algebraic generalization. However, as the course progressed, other representations were valued for expressing generalizations. This indicates that the teachers focus appears to have moved from a stricter notion on the use of algebraic language to generalize to a broader notion that considers that generalizations may be expressed in a variety of representations.

The justifications made by the students were object of analysis by the teachers, a recurrent element in the presentations of Into Practice I and II. In their analysis, the teachers referred ways of justification, such as the use of generic examples, the properties of mathematical objects, and logical coherence, including proof by contradiction. More than giving particular importance to symbolic representation, the teachers emphasized the students' capacity to justify using several representations.

The teachers made a clear distinction between generalizing and justifying. They agreed that, while justification through the verification of specific cases is not acceptable in mathematics, it may be used to make generalizations.

As a result of the sharing of Into Practice moments, the teachers assigned a moderate importance to formality, both in generalizing and in justifying. They accepted the use of natural language and various representations as valid forms for the students to present these mathematical reasoning processes. They regarded these representations as an asset. They considered that helping the students not to lose the meaning of the situation, these representations contribute to students' mathematical learning with understanding (as indicated in Lannin et al. (2011)). In addition, they assumed that these representations are better suited to the age of the students and to the level of development of their mathematical learning (as in Stylianides (2008)).

The development observed in the teachers concerning how they recognize and speak about generalization and justification seems to be strongly related to the way the course was designed. Offering opportunities to reflect about classroom episodes and analysing them with the support of theoretical ideas taken from the texts that they read and that were discussed in the sessions, may have allowed teachers to give a new meaning and a more focused attention to the reasoning processes. Also, to plan collaboratively, to put into practice and to reflect with others, may have contributed to the professional development of participants. This is in line with important features identified in professional development processes (e.g., Borko et al. (2010) and Smith (2001)). Acknowledging the importance of developing these mathematical reasoning processes in students, the teachers aimed to design tasks that would be more suitable to their particular students, and did not use the tasks that the course offered blindly. Putting Into Practice allowed also the teachers to analyse a large set of students' productions increasing the possibility of finding a larger diversity of ways and levels of complexity of the reasoning processes. 


\section{CONCLUSIONS}

Prior research on the subject of this study, regarding primary teachers, focused mainly on their understanding of reasoning processes (e.g., Herbert and Bragg (2020)). For middle and secondary school teachers, the focus has been mainly on the processes of mathematical reasoning, namely generalization (e.g., El Mouhayar (2020)) or justification (e.g., Sowder \& Harel, 1998) separately. Thus, the contribution of this study is to present not only the understanding of reasoning processes, but also the evolution of middle and secondary school teachers who participated in a course in relation to both generalization and justification. Also, this study contributes with a unified analytical framework regarding these two central mathematical reasoning processes that provides a more cohesive perspective about teachers' understanding of mathematical reasoning.

In this course, the teachers identified and characterized the generalizing and justifying processes through the analysis, sharing and discussion of ideas and through the analysis of students' solutions of tasks, intentionally designed to promote mathematical reasoning (Smith, 2001; Weiss \& Pasley, 2006). As teachers worked collaboratively throughout the course, the option taken in this study was to consider all participating teachers in order to have a global idea of their evolution. However, this study may be developed with the study of individual teachers, as case studies. The present study provides insights about the development of teachers' understanding of generalizing and justifying processes and highlights their ability to foster and identify these processes in the work with their students.

Author contributions: All authors have sufficiently contributed to the study, and agreed with the results and conclusions.

Funding: This paper is supported by FCT - Fundação para a Ciência e Tecnologia, through Project REASON - Mathematical Reasoning and Teacher Education (Project IC\&DT - AAC 02/SAICT/2017 and PTDC/CED-EDG/28022/2017).

Declaration of interest: No conflict of interest is declared by authors.

\section{REFERENCES}

Bardin, L. (2003). L'Analyse de contenu [Content analysis] (10th ed.). Presses Universitaires de France.

Borko, H., Jacobs, J., \& Koellner, K. (2010). Contemporary approaches to teacher professional development. International Encyclopedia of Education, 7, 548-556. https://doi.org/10.1016/ B978-0-08-044894-7.00654-0

Brodie, K. (2010). Teaching mathematical reasoning in secondary school classrooms. Springer US. https:/ / doi.org/10.1007/978-0-387-09742-8

Davidson, A., Herbert, S., \& Bragg, L. A. (2019). Supporting elementary teachers' planning and assessing of mathematical reasoning. International Journal of Science and Mathematics Education, 17, 1151-1171. https://doi.org/10.1007/s10763-0189904-0

Davis, P., \& Hersh, R. (1986). A experiência matemática [The math experience] (3rd ed.). Francisco Alves.

El Mouhayar, R. (2020). Investigating quality of class talk in grade 7: The case of pattern generalization. International Journal of Science and Mathematics Education, 19, 1015-1036. https:// doi.org/10.1007/ s10763-020-10092-8

Ellis, A. (2007). Connections between generalizing and justifying: Students' reasoning with linear relationships. Journal for Research in Mathematics Education, 38, 194-229. https://doi.org/10.2307/ 30034866

Ellis, A., Ozgur, Z., \& Reiten, L. (2019). Teacher moves for supporting student reasoning. Journal of Mathematics Education Research, 31, 107-132. https:/ / doi.org/10.1007/s13394-018-0246-6

Herbert, S. \& Bragg, L. A. (2020). Factors in a professional learning program to support a teacher's growth in mathematical reasoning and its pedagogy. Mathematics Education Research Journal, 33, 409-433. https:// doi.org/10.1007/s13394-020-00310-5

Hoyles, C., \& Küchemann, D. (2002). Student's understanding of logical implication. Educational Studies in Mathematics, 51(3), 193-223. https:/ / doi.org/10.1023/A:1023629608614

Jeannotte, D., \& Kieran, C. (2017). A conceptual model of mathematical reasoning for school mathematics. Educational Studies in Mathematics, 96, 1-16. https:/ / doi.org/10.1007/s10649-017-9761-8

Keazer, L. (2014). Teachers' learning journeys toward reasoning and sense making. In J. Lo, K. Leatham, \& L. Zoest (Eds.), Research trends in mathematics teacher education (pp. 155-180). Springer International. https://doi.org/10.1007/978-3-31902562-9_9

Kilpatrick, J., Swafford, J., \& Findell, B. (2001). Adding it up: Helping children learn mathematics. National Research Council.

Lannin, J., Ellis, A., \& Elliot, R. (2011). Developing essential understanding of mathematical reasoning for teaching mathematics in Prekindergarden - grade 8. NCTM.

Lithner, J. (2008). A research framework for creative and imitative reasoning. Educational Studies in Mathematics, 67, 255-276. https:/ / doi.org/10.1007/ s10649-007-9104-2

Mata-Pereira, J., \& Ponte, J. P. (2012). Raciocínio matemático em conjuntos numéricos: Uma investigação no $3 .^{\circ}$ ciclo [Mathematical reasoning in numerical sets: An investigation in the 3rd cycle]. Quadrante, 21(2), 81-110. https://doi.org/10.48489 /quadrante.22879 
Mata-Pereira, J., \& Ponte, J. P. (2017). Enhancing students' mathematical reasoning in the classroom: Teacher actions facilitating generalization and justification. Educational Studies in Mathematics, 96(2), 169-186. https://doi.org/10.1007/s10649017-9773-4

Mata-Pereira, J., \& Ponte, J. P. (2018). Teacher's actions to promote students' justification. Acta Scientiae, 20(3), 487-505. https://doi.org/10.17648/acta.scientiae. v20iss3id3910

National Governors Association Center for Best Practices \& Council of Chief State School Officers. (2010). Common Core State Standards for Mathematics.

OECD. (2018). PISA 2021 mathematics framework (Draft). https:/ / pisa2021-maths.oecd.org/files/PISA\% 202021\%20Mathematics\%20Framework\%20Draft. pdf

Pólya, G. (1945). How to solve it: A new aspect of the mathematical method. Princeton University Press. https: / / doi.org/10.1515/9781400828678

Pólya, G. (1990). Mathematics and plausible reasoning. Princeton University Press.

Schwandt, T. (1994). Constructivist, interpretivist approaches to human inquiry. In N. Denzin, \& Y. Lincoln (Eds.), Handbook of qualitative research (pp. 118-137). SAGE.

Silva, A. P. (2009). A problemática da descoberta e da prova [The problematic of discovery and proof]. Educação \& Matemática, 101, 37-41.
Smith, M. (2001). Practice-based professional development for teachers of mathematics. NCTM.

Sowder, L., \& Harel, G. (1998). Types of students' justifications. The Mathematics Teacher, 91(8), 670675. https:/ / doi.org/10.1007/s10649-005-2532-y

Stylianides, G. J. (2008). An analytic framework of reasoning-and-proving. For the Learning of Mathematics, 28(1), 9-16. https://doi.org/10.1007/ s10763-013-9409-9

Stylianides, G. J., Stylianides, A. J., \& Shilling-Traina, L. N. (2013). Prospective teachers' challenges in teaching reasoning-and-proving. International Journal of Science and Mathematics Education, 11(6), 1463-1515.

Watson, F. R. (1980). The role of proof and conjecture in mathematics and mathematics teaching. International Journal of Mathematics Education and Technology, 11(2), 163-167. https://doi.org/ 10.1080/0020739800110202

Weiss, I., \& Pasley, J. (2006). Scaling up instructional improvement through teacher professional development: Insights from the local systemic change initiative. CPRE Policy Briefs, 44, 1-16. https:/ / doi.org/10.12698/cpre.2006.rb44

Widjaja, W., Vale, C., Herbert, S., Loong, E., \& Bragg, L. A. (2020). Linking comparing and contrasting, generalising and justifying: a case study of primary students' levels of justifying. Mathematics Education Research Journal, 33(1), 1-23. https://doi.org/ $10.1007 /$ s13394-019-00306-w

\section{https://www.ejmste.com}

